\title{
PENGEMBANGAN SISTEM INFORMASI PADA MANAJEMEN GUDANG DALAM INDUSTRI MANUFAKTUR MENGGUNAKAN TEKNOLOGI SOA DAN RFID
}

\author{
Rudy Tjahyadi \\ Program Sistem Informasi, Program Studi Sistem Informasi, Universitas Bina Nusantara \\ Jln. K.H. Syahdan No. 9, Palmerah, Jakarta Barat, 11480 \\ Telp. (021) 5345830 \\ E-mail: rudy.t@binus.edu
}

\begin{abstract}
ABSTRAKSI
Dalam perusahaan manufaktur, kecepatan adalah salah satu komponen keunggulan yang dapat membawa perusahaan untuk dapat bersaing di dunia bisnis. Gudang adalah area penting yang menyimpan bahan dasar dan hasil produksi, untuk itu dibutuhkan kebutuhan Sistem Manajemen Gudang dengan dukungan teknologi Radio Frequency Identification (RFID) yang juga dapat diintegrasikan dengan sistem ERP pada suatu perusahaan. Untuk membangun aplikasi WMS dengan teknologi RFID dan dapat berintegrasi dengan ERP, dibutuhkan metode SOA yang digunakan untuk desain aplikasi. Service Oriented Modeling And Architecture (SOMA) adalah metode pengembangan perangkat lunak berbasis SOA yand dapat mengintegrasikan sistem WMS yang dikembangkan dengan WMS mobile Web dan aplikasi ERP yang telah ada sebelumnya. Dengan pengembangan sistem WMS yang didukung RFID dan berbasis SOA dengan metode SOMA diharapkan kecepatan dan keakuratan data transaksi dapat tercapai sehingga dapat membantu perusahaan bersaing dengan pesaing.
\end{abstract}

Kata Kunci : SOA, SOMA, Sistem Manajemen Gudang, RFID 


\section{PENDAHULUAN}

Dalam dunia manufaktur, kecepatan pada saat ini merupakan nilai yang sangat penting dalam mendukung perusahaan agar dapat bersaing di dunia bisnis, bagaimana produksi dapat diselesaikan tepat waktu dengan sedikit kelebihan jumlah produksi dan dengan perhitungan pemulihan produksi yang tepat sehingga biaya yang di butuhkan lebih hemat dan efisien, untuk mendukungnya harus dimulai dari gudang karena gudang merupakan tempat penyimpanan bahan produksi dimana komposisi dan pengambilan barang yang benar serta akurat adalah hal yang harus dicapai untuk mendukung pencapaian kecepatan dan akurasi. Pada perusahaan tempat studi kasus ini telah menerapkan Enterprise Resource Planning (ERP) dimana terdapat modul yang mendukung proses inventori gudang dan Perencanaan Permintaan Material (MRP) tetapi memiliki kesulitan dalam mengelola barang secara fisik dan mengelola barang merupakan masalah yang cukup sulit dipecahkan.

Sistem Manajemen Gudang/Warehouse Management System(WMS) dapat membantu organisasi dalam pengaturan barang menjadi lebih cepat dan efisien. Namun untuk mendukung terciptanya sistem WMS yang cepat dan efisien dibutuhkan Radio Frequency Identification (RFID) yang berfungsi sebagai pengganti barcode, RFID adalah salah satu teknologi yang memberikan kecepatan transfer data dan data jumlah barang yang lebih cepat sehingga bisa membantu mencapai efisiensi dan kecepatan proses transaksi pada sistem WMS. Perusahaan yang bergerak di bidang industri seperti pabrik sepatu perlu didukung proses bisnis perusahaan yang bergerak di perusahaan manufaktur dengan menerapkan WMS yang juga didukung oleh RFID sehingga diharapkan dapat dengan mudah mencari dan mengambil barang menggunakan First In First Out (FIFO), membantu dalam analisis kapasitas produksi dan mempercepat operasional di gudang. Metode arsitektur berorientasi layanan (SOA) di dalamnya cukup populer di era sekarang, $S O A$ merupakan pendekatan dalam mendesain aplikasi menggunakan komponen-komponen yang telah ada sebelumnya.

Komponen ini menyediakan jenis layanan bisnis tertentu, memungkinkan beberapa proses bisnis di mana ada banyak aplikasi yang dianggap sebagai layanan yang dapat diintegrasikan dalam mendukung proses bisnis organisasi, dengan data SOA dan system yang ada akan membentuk yang proses yang paling efektif. Service Oriented Modeling Architecture (SOMA) adalah metode yang digunakan untuk merancang perangkat lunak berbasis SOA, SOMA mendefinisikan teknik utama dan menjelaskan peran pada proyek $S O A$ dan Work Breakdown Structure (WBS). Dengan metode yang akan di gunakan SOMA, diharapkan integrasi antara mobile WMS, WMS Web, dan ERP dapat terwujud dengan harapan dapat menyelesaikan masalah dalam meningkatkan kecepatan dan keakuratan data transaksi.

\section{METODE PENELITIAN}

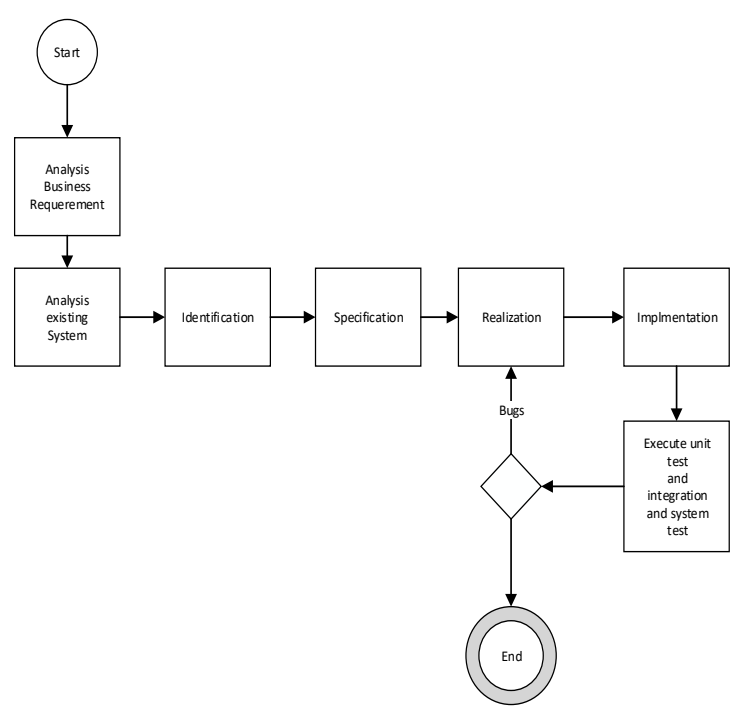

Gambar 1. Tahapan Penelitian

Kerangka Langkah Penelitian dikembangkan berdasarkan kebutuhan studi kasus Perusahaan tentang aplikasi WMS dengan dukungan RFID yang akan membantu perusahaan dalam membuat indikator efektivitas dari business proses di Gudang agar dapat beroperasi secara efisien dan efektif dengan menggunakan metode SOMA serta dapat diintegrasikan dengan aplikasi ERP yang ada.

Tahapan yang akan dilakukan dalam penelitian ini sesuai dengan Kerangka Langkah Penelitian (Gambar 1) adalah sebagai berikut:

1. Analisis kebutuhan bisnis

Pada tahap ini akan dilakukan pengumpulan kebutuhan bisnis dalam pertemuan yang dihadiri oleh manajer dan pengguna terkait.

\section{Analisis Sistem yang Ada}

Pada tahap analisis system yang ada saat ini, akan dilakukan dengan melakukan analisa terhadap 
sistem yang sudah berjalan khususnya sistem Gudang pada ERP yang ada.

\section{Identifikasi}

Tahap awal SOMA dilakukan setelah analisis sistem yang ada dengan mengidentifikasi apa yang belum ada pada sistem yang sekarang dimana pada tahap ini akan dianalisis apa yang dibutuhkan oleh bisnis dan analisis sistem yang ada untuk mendapatkan lapisan layanan pada aplikasi WMS dengan membuat diagram rantai nilai, model komponen bisnis dan penentuan bagaimana melakukan pemodelan layanan tujuan yang kemudian dianalisis dan didekomposisi sehingga menghasilkan layer layanan.

\section{Spesifikasi}

Pada tahap spesifikasi akan dianalisis proses bisnis, mendokumentasikan antarmuka layanan agar dapat menghasilkan layer komponen dan operasi yang diinginkan serta hubungannya dengan layer layanan

\section{Realisasi}

Pada tahap realisasi dilakukan Kelayakan Teknis Eksplorasi untuk mendapatkan solusi dari beberapa potensial solusi dan kemudian dianalisis untuk membuat layer stack solusi SOA Detail.

\section{Implementasi}

Pada tahap ini akan dilakukan implementasi dari hasil analisis sebelumnya dengan cara membuat aplikasi web WMS dan Mobile serta layanan web dan ETL (Extract Transform Loading) yang membutuhkan proses integrasi, dan setelah aplikasi selesai maka akan dilakukan pengujian sistem dengan UAT (User Acceptance Test).

\section{HASIL DAN DISKUSI}

\section{A. Analisa Kebutuhan Bisnis}

Berikut ini adalah hasil yang diperoleh dari wawancara di tempat penelitian perusahaan untuk kebutuhan bisnis, penempatan barang sesuai dengan lokasi dan rak masing-masing, dapat ditampilkan dalam bentuk peta lokasi barang. Pemberitahuan jika terjadi kesalahan penempatan barang. Lokasi dan jumlah stok yang dapat diketahui dengan cepat dan akurat. Dapat mengembalikan sisa stok ke tempat semula (lokasi barang induk) dengan cepat dan akurat. Dapat mengetahui dengan cepat jika ada barang yang pindah lokasi atau dicampur dengan yang lain, disertai dengan riwayat log (Disesuaikan per merek). Identifikasi rak dapat dibuat fleksibel, saat membuat rak baru atau rak lama. Diperlukan analisis kapasitas gudang menggunakan kapasitas barang. Penerimaan barang dapat dilakukan dengan cepat dan tepat sesuai dengan permintaan. Pemberitahuan muncul ketika ada perbedaan.

Pengeluaran barang bisa dilakukan dengan cepat dan tepat sesuai permintaan. Pemberitahuan muncul ketika ada perbedaan. Pengeluaran dapat dilakukan sesuai dengan sistem FIFO bila diperlukan. Pemberitahuan muncul ketika ada perbedaan. Output barang yang dicampur dalam satu palet dapat diidentifikasi sebagai satu kesatuan ID / Pallet, dan dapat diketahui detail item per palet tersebut. Item subkontrak (Warna layanan, Semprot, Laminating, Footed, Emboss, Benang, Atas, Eva) dapat diidentifikasi hingga pengembalian. Notifikasi bila melebihi batas waktu pengerjaan. Pengembalian barang yang tersisa dapat dilakukan dengan cepat dan akurat sesuai dengan barang induk sebelumnya. Penghitungan ulang barang (penghitungan stok) dapat dilakukan dengan cepat dan akurat. Dapat menyortir / mengubah status barang aktif dan DROP (nonaktif), kelebihan pemotongan, penolakan, FOC, karantina. Pemberitahuan penyimpanan kedaluwarsa, dan informasi tentang barang bergerak cepat / lambat. Dapat diketahui transfer barang, beserta riwayat lognya, sehingga mudah melacak proses mutasinya. Staf gudang dapat melakukan perbaikan data hanya melalui proses persetujuan. Pengguna dapat mengetahui posisi dan stok barang secara real-time, cepat dan akurat di mana pun berada melalui BASE WEB. Fitur aplikasi web / desktop dapat direpresentasikan dalam Perangkat Seluler. Program aplikasi memiliki fungsi manajemen gudang standar (Lembar: WMS)

Information Board (TV) sebagai peringatan informasi tentang status barang IN-OUT, dengan alarm suara ketika ada ketidakkonsistenan. Memiliki metode identifikasi dan keamanan pengguna dengan otorisasi. Data dapat disimpan menggunakan versi database MS SQL 2008 R2. Data master dan transaksi dapat diunggah dan diunduh ke Excel, dicetak melalui printer / labeler yang diperlukan dengan otorisasi. Semua data dalam WMS dapat diintegrasikan secara real-time IN-OUT dengan ERP 


\section{B. Analisis Sistem yang sudah ada}

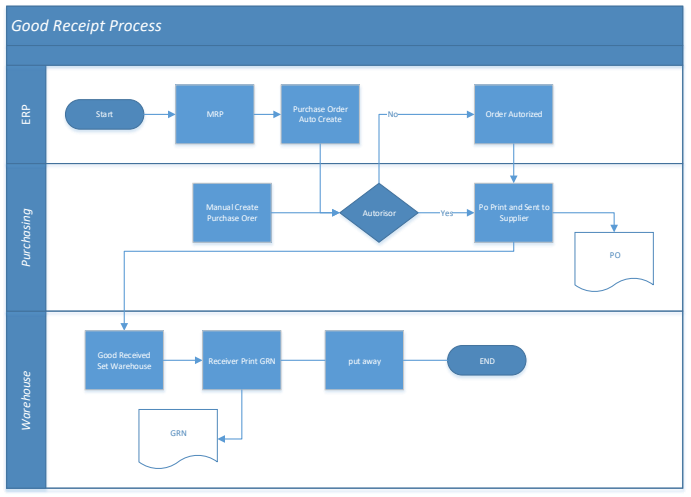

Gambar 2. Alur Barang pada System yang ada

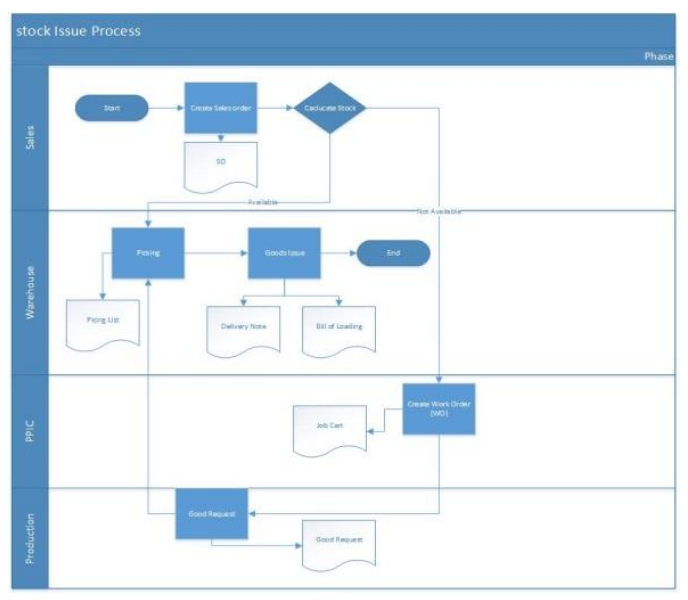

Gambar 3. Alur Sistem untuk Stok yang bermasalah

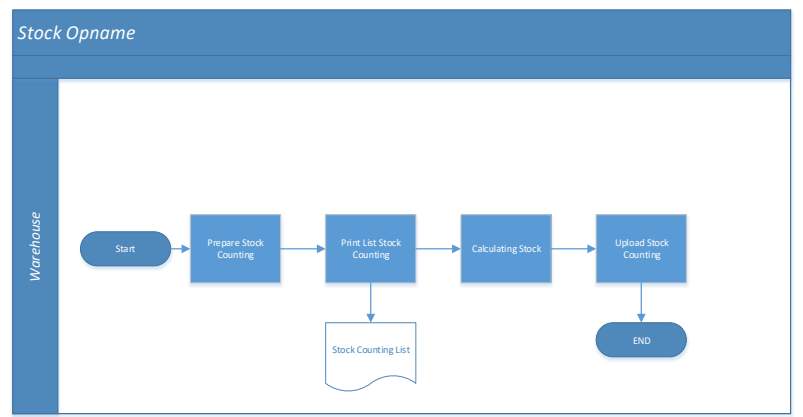

Gambar 4. Alur penghitungan Stok pada Sytem yang ada

Dalam prosesnya baik menerima barang pada gambar 3 dan memproses stok mengeluarkan barang gambar 4 yang diterima dan dalam data di gudang sebagai stok dalam sistem ERP pada proses ketika mengambil stok barang di FIFO dan mencari barang akan sulit karena stok dikelola dengan data dalam sistem sementara secara fisik ada kemungkinan salah ambil barang serta tidak adanya alamat yang digunakan dalam sistem stok, proses penghitungan stok juga masih terlalu lama dan tidak bisa dikelurakan per rak. Dengan menggunakan RFID dan WMS dalam penghitungan stok diharapkan dapat dilakukan dengan cepat dan akurat.

\section{Identifikasi}

Proses desain dan pengembangan aplikasi WMS yang akan diintegrasikan dengan sistem ERP serta aplikasi mobile $W M S$ akan menggunakan metode (SOMA) sedangkan untuk proses perancangan basis data akan menggunakan metode Bottom-Up, serta pengujian menggunakan metode Black-Box.

\section{Model Rantai Nilai}

Untuk lebih menggambarkan proses bisnis tingkat tinggi dalam studi kasus Perusahaan akan ditampilkan diagram Value Chain, Value Chain akan menggambarkan diagram kegiatan utama yang menjadi pilar rantai nilai dan aktivitas pendukung di perusahaan.

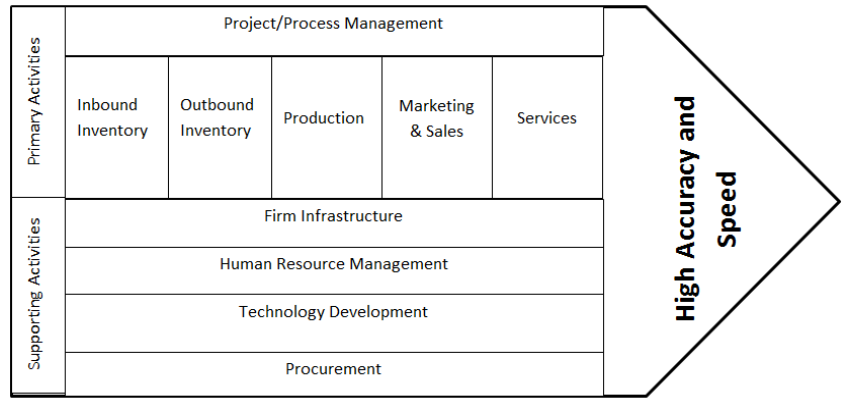

Gambar 5. Model Rantai Nilai

\section{Model Komponen Bisnis}

Gambar 6 menggambarkan Model Komponen Bisnis yang menunjukkan area penting dari proses bisnis yang harus diprioritaskan baik komponen internal maupun komponen eksternal dari kumpulan komponen yang juga dihilangkan apa yang sudah ada di model Rantai Nilai. Diagram angka 8 ditentukan oleh Area penting yang melibatkan Manajemen dan departemen IT perusahaan yang harus sesuai dengan strategi utama Perusahaan yaitu tingkat akurasi dan kecepatan yang tinggi, kemudian area masuk dan keluar dalam arti proses yang sangat penting untuk mencapai akurasi dan kecepatan. Di mana bahan dasar yang akan menjadi komponen produksi harus dipilih secara akurat serta mempercepat pencarian barang ketika penyimpanan Outbond berdasarkan Model Rantai Nilai. 


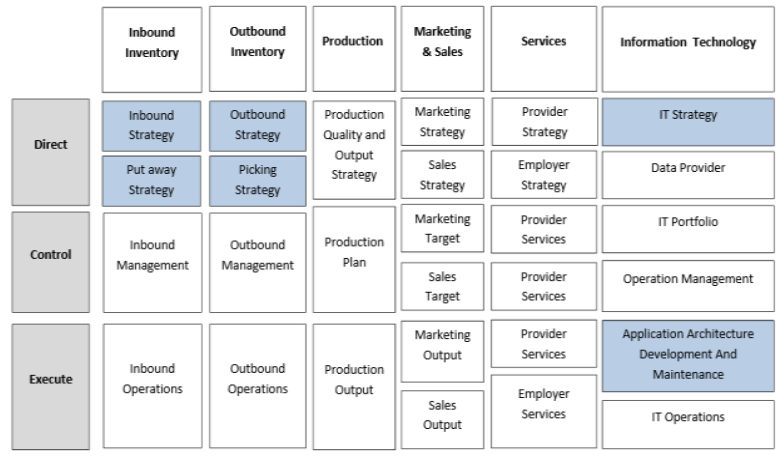

Gambar 6. Model Komponen Bisnis

3. Membuat Tujuan Model Pelayanan

Membuat Goal-Service Modeling dari desain studi kasus Arsitektur Berorientasi Layanan adalah untuk meningkatkan kecepatan dan ketepatan dengan melakukan rekayasa ulang serta pengembangan pada sistem yang sudah ada.

4. Layanan Refactoring Dan Rasionalisasi Tahap ini adalah tahap akhir dari proses identifikasi di mana proses tersebut digunakan untuk menentukan layanan apa yang dibutuhkan dalam aplikasi $W M S$ yang akan menjadi portofolio dari model layanan.

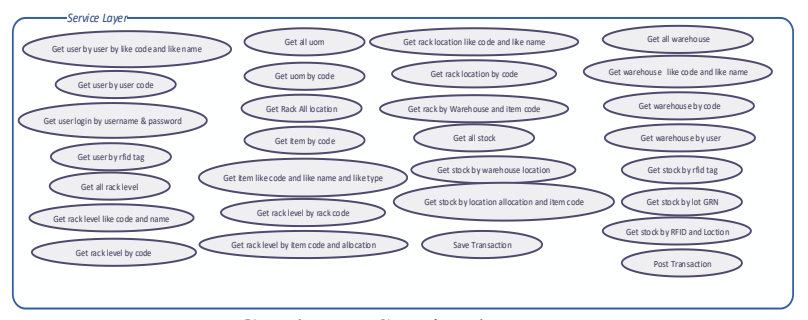

Gambar 7. Service layer

\section{Spesifikasi}

Pada tahap perancangan spesifikasi komponen layanan yang dapat dari hasil identifikasi proses yang dilakukan sebelumnya, hasil dari fase layanan digunakan untuk mencapai pemodelan layanan target dan juga penyusunan arsitektur arsitektur.

\section{Menganalisis Subsistem}

Fase analisis subsistem adalah tahap di mana layanan yang telah dirancang pada fase sebelumnya dijelaskan secara lebih rinci termasuk operasi dan dokumen di dalamnya.

- Model Dokumen

Hasil dari proses yang diidentifikasi juga akan ditentukan dalam dokumen yang relevan yang dapat menggambarkan seluruh proses operasi atau hasil dari operasi yang terbentuk dari proses operasional.

Dokumen ini terdiri dari dokumen hasil transaksi yang diterima, Pergerakan Stok, Penghitungan Stok, Pencarian Material dan Stock Issue yang diambil dari transaksi yang hebat di gudang seperti yang akan ditunjukkan pada gambar no.

\begin{tabular}{|c|c|c|c|}
\hline $\begin{array}{l}\text { <<Document }> \\
\text { Item GRN }\end{array}$ & $\begin{array}{c}\text { «<Document }> \\
\text { Rack List }\end{array}$ & $\begin{array}{l}\text { «<Document }>> \\
\text { Rack Level List }\end{array}$ & $\begin{array}{l}\text { <<Document }> \\
\text { Stock Rack }\end{array}$ \\
\hline $\begin{array}{c}\text { <<Document»> } \\
\text { Stock Rack Level } \\
\text { List }\end{array}$ & $\begin{array}{l}\text { < Document»> } \\
\text { Stock Info }\end{array}$ & $\begin{array}{l}\text { <<Document }>> \\
\text { Transaction Good } \\
\text { Receipt }\end{array}$ & $\begin{array}{l}\quad<\text { Document }> \\
\text { Transaction Good } \\
\text { Receipt Item List }\end{array}$ \\
\hline $\begin{array}{l}<<\text { Document } \gg \\
\text { Transaction Stock } \\
\text { Movement }\end{array}$ & $\begin{array}{c}\ll \text { Document }> \\
\text { Transaction Stock } \\
\text { Movement Item } \\
\text { List }\end{array}$ & $\begin{array}{c}<<\text { Document } \gg \\
\text { Transaction Stock } \\
\text { Movement Item } \\
\text { List }\end{array}$ & $\begin{array}{l}\text { <<Document»> } \\
\text { Rack Suggestion } \\
\text { List }\end{array}$ \\
\hline $\begin{array}{c}\text { <<Document»> } \\
\text { Rack Level } \\
\text { Suggestion List }\end{array}$ & $\begin{array}{c}\text { « Document }> \\
\text { Transaction Stock } \\
\text { Opname }\end{array}$ & $\begin{array}{l}\text { <<Document»> } \\
\text { Transaction Stock } \\
\text { Opname Item List }\end{array}$ & $\begin{array}{c}\text { <Document»> } \\
\text { Transaction Stock } \\
\text { Issue }\end{array}$ \\
\hline $\begin{array}{l}<<\text { Document }> \\
\text { Transaction Stock } \\
\text { Issue Item List }\end{array}$ & & & \\
\hline
\end{tabular}

Gambar 8. Model Dokumen

2. Proses Bisnis

Sebuah studi tentang Arsitektur Berorientasi Layanan adalah pose bisnis yang dibuat menjadi perhatian adalah proses persediaan masuk di mana ada proses menerima dan menyimpan, proses persediaan keluar di mana ada proses pengambilan dan penerbitan dan proses Bahan Pencarian dan penghitungan stok.

Tujuan dari proses bisnis adalah bagaimana proses penerimaan barang yang lebih mudah dan penempatan barang yang akan menunjukkan saran penempatan lokasi, proses pengambilan keputusan barang akan menunjukkan saran lokasi barang dan mempermudah pencarian barang dan stok penghitungan yang lebih mudah dan akurat

\section{Layanan Refactor Dan Rasionalisasi}

Tahap ini adalah tahap akhir dari spesifikasi yang akan membentuk layanan yang terhubung sesuai dengan komponen secara lebih rinci berdasarkan pada tahap spesifikasi yang telah dilakukan sebelumnya.

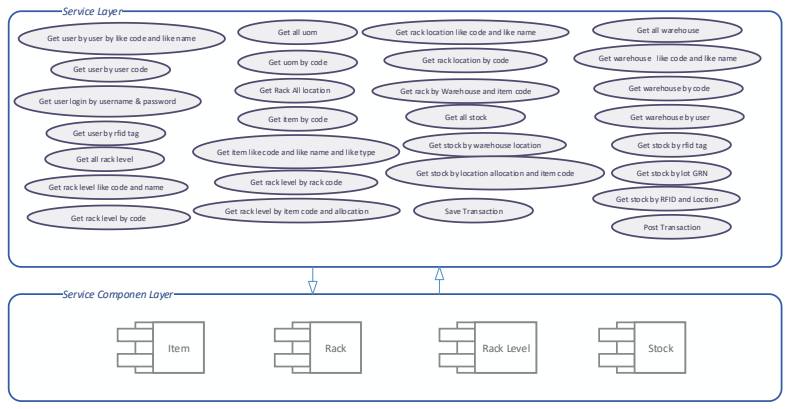

Gambar 9. Component Layer pada SOA References Architecture 


\section{E. Realisasi}

Pada tahap ini, berfungsi untuk mendefinisikan atau menghubungkan ke layanan yang telah ditentukan oleh komponen yang akan diterapkan dalam implementasi yang dijelaskan dalam arsitektur SOA. Arsitektur Referensi SOA akan menjelaskan secara rinci setiap arsitektur lapisan/layer yang dibentuk untuk diimplementasikan selama implementasi.

- Detail keseluruhan lapisan SOA

Rincian dari lapisan solusi SOA pada dasarnya terdiri dari 6 lapisan rumah termasuk lapisan konsumen, lapisan integrasi, lapisan proses bisnis, lapisan layanan, lapisan komponen dan lapisan operasi. Gambar di bawah ini menggambarkan Arsitektur Referensi SOA yang diusulkan dalam proses penyelidikan dengan menerapkan SOA yang disesuaikan dengan proses bisnis Manajemen Layanan Pelanggan dalam studi kasus Perusahaan.

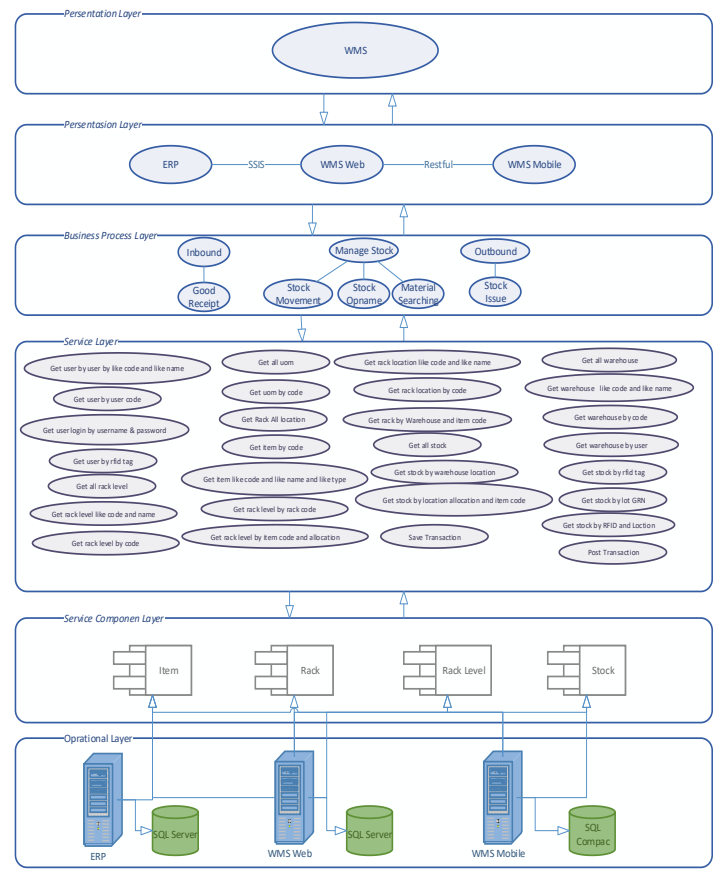

Gambar 10. Detail SOA solution stack layers

\section{F. Implementasi}

Tahap implementasi adalah tahap pembentukan layanan yang dihasilkan dari analisis pada tahap sebelumnya dalam makalah ini akan dibahas dalam pembuatan layanan web untuk integrasi antara perangkat mobile WMS dibangun pada platform windows $C E$ menggunakan database $S Q L$ web Compact WMS di bangun dengan database $S Q L$ Server ASP.net dan MSSQL dan pembuatan SSIS untuk integritas antara ERP dan WMS Web.

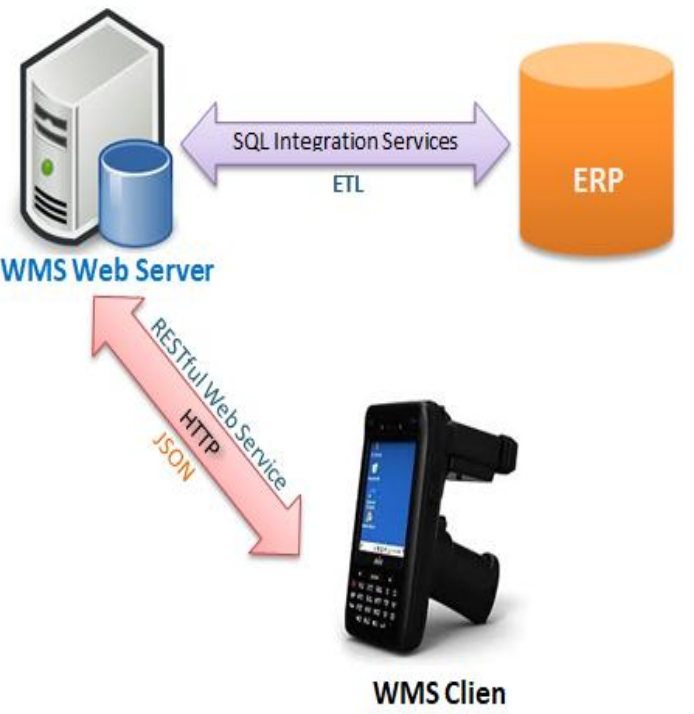

Gambar 11. Model Integrasi dari penelitian ini

Seperti digambarkan dalam gambar 11 dimana proses akan menggunakan layanan web Restful untuk menghubungkan web $W M S$ dengan ponsel $W M S$ dan untuk menghubungkan web WMS dengan ERP yang ada akan dilakukan dengan menggunakan Layanan Integrasi $S q l$.

1. Membangun, Menghasilkan dan Merakit Layanan

Pada tahap ini adalah tahap di mana layanan web dan SSIS dibuat sesuai dengan arsitektur SOA pada fase sebelumnya.

- ETL

Untuk integrasi antara ERP dan WMS dilakukan dengan ETL yang dibangun menggunakan SSIS (Sql Service Integration Services), dimana dalam implementasi ERP yang digunakan oleh perusahaan saat ini tidak ada fitur integrasi yang tersedia sehingga dilakukan integrasi antara 2 sistem yang ada. Berbeda dengan ETL buatan untuk menyelaraskan data master antara ERP dan $W M S$. ETL yang akan dibangun meliputi Item data master, Item GRN dan gudang.

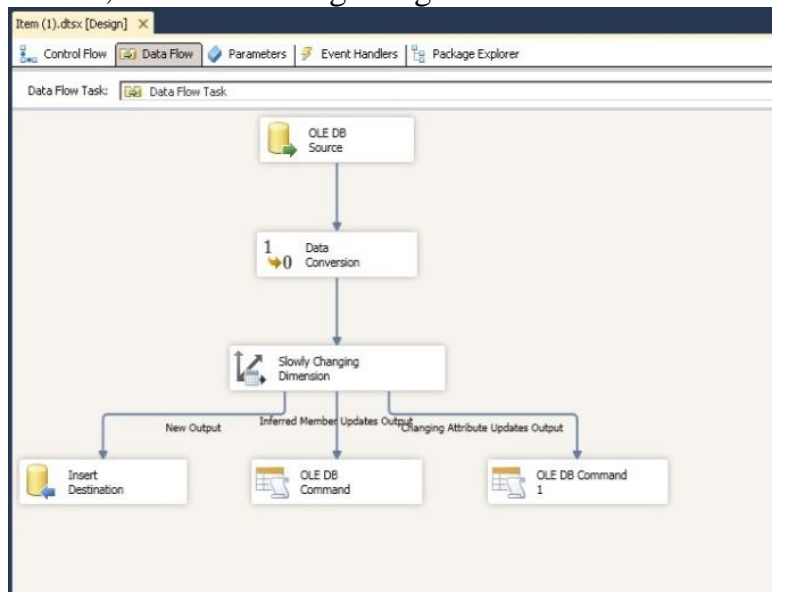


Gambar 12: ETL menggunakan Sql Server

Integration Services

\section{- Rest Web Service}

Dalam layanan web yang digunakan untuk integrasi antara mobile dan WMS Web, akan menggunakan metode tenang yang dibangun menggunakan ASMX (Active Server Methods Extensions) / .NET Platform dan WCF (Windows Communication Foundation) untuk menghasilkan REST menggunakan format dan pengembangan json menggunakan Visual Studio IDE.

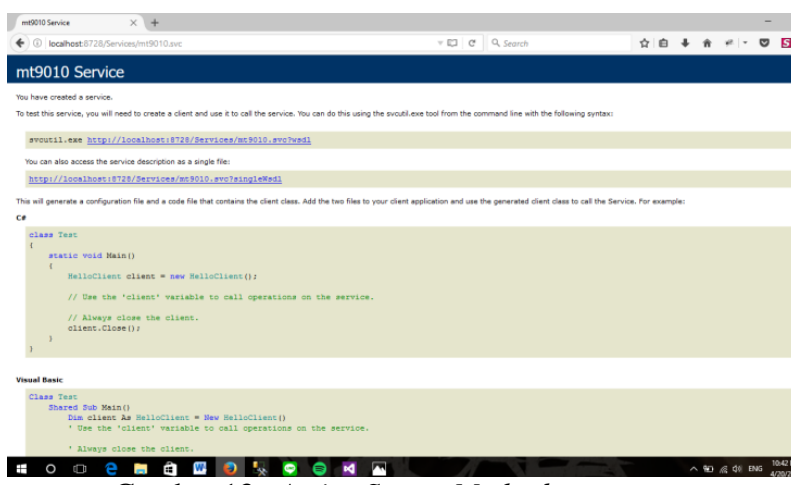

Gambar 13. Active Server Methods user

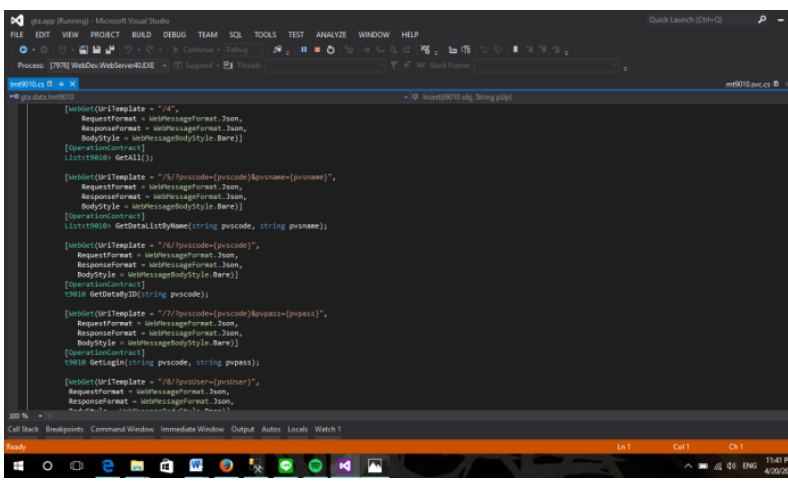

Gambar 14. Windows Communication Foundation

- Implementasi Desain pada Layar

Gambaran yang telah dibuat di ponsel Windows $C E$ digunakan untuk transaksi RFID seluler di gadget studi kasus Perusahaan yang akan diintegrasikan dengan Aplikasi Web WMS dan ERP.

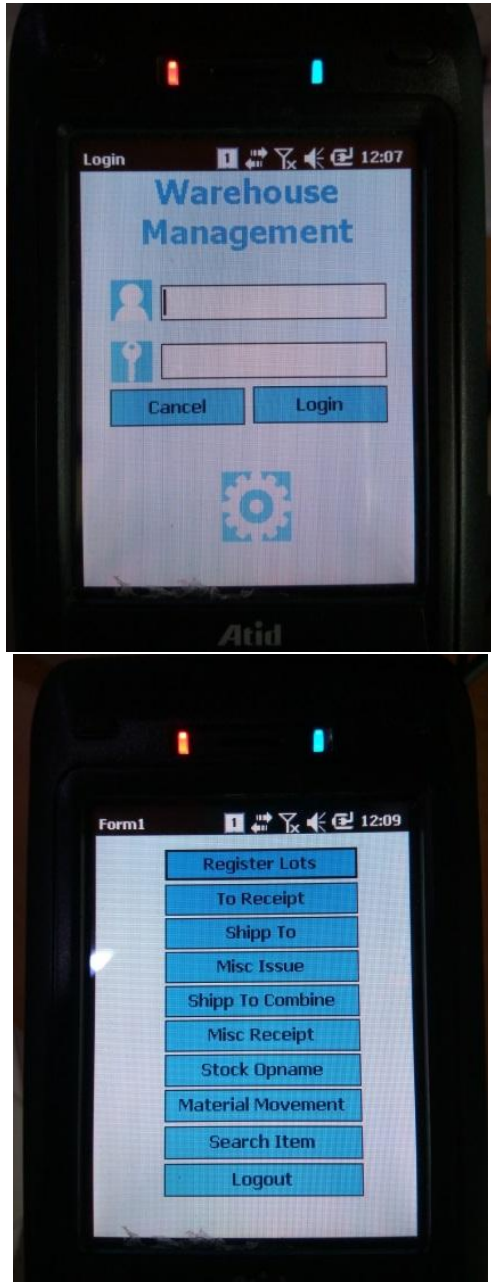

Gambar 15. UI Login dan Menu pada Mobile WMS

Pada tampilan menu utama aplikasi mobile WMS terdapat sub menu termasuk Register Lot, To Receipt, Shipp To, dll. Hasil penerbitan Untuk Menggabungkan Shipping, Misc Receipt, Stock Opname / Menghitung Stok, Pergerakan Material, dan fitu untuk mencari item. 


\section{G. Evaluation}

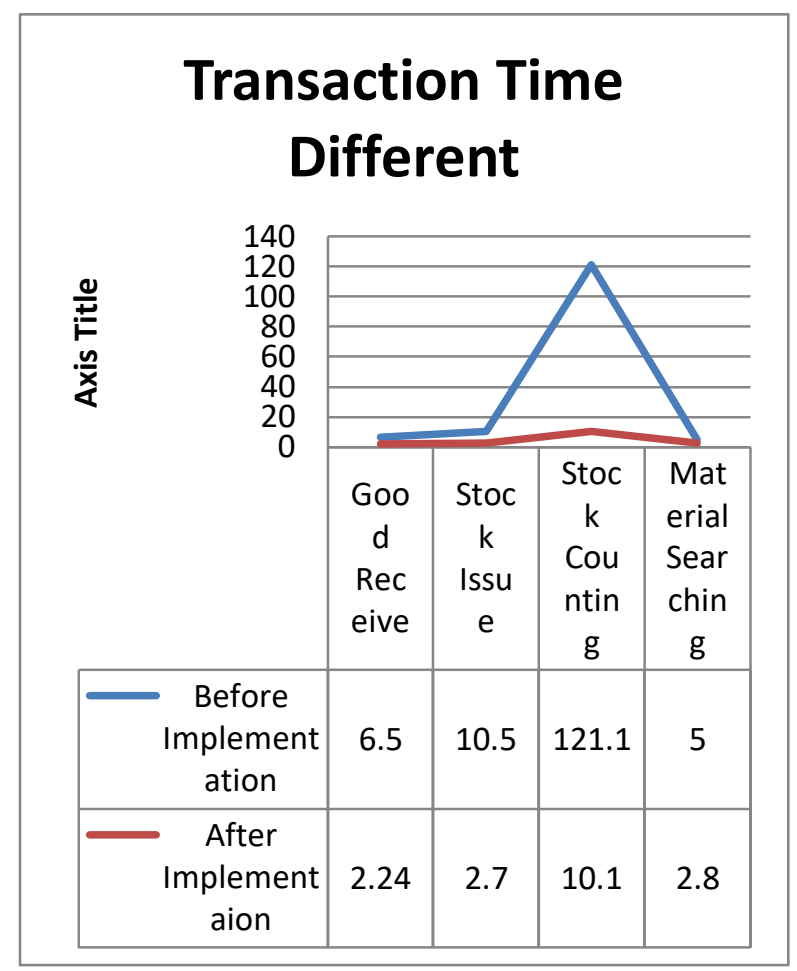

Gambar 16. Perbedaan Waktu Transaksi

Gambar 16 menjelaskan jumlah perbedaan waktu dari setiap transaksi pada saat sebelum dan sesudah implementasi implementasi WMS, Perbedaan waktu terbesar adalah 111 menit dalam transaksi opname / penghitungan stok. Perbedaan dapat dilihat pada kecepatan transaksi yang dihasilkan dengan menerapkan WMS dan RFID semakin meningkat, dengan adanya aplikasi Metode RFID fifo dapat dijalankan untuk memonitor barang fisik dan dapat meminimalkan kesalahan, dengan aplikasi $S O A$ yang digunakan untuk integrasi antara $E R P$ dan $W M S$ maka input data dapat menjadi lebih mudah tanpa mengubah sistem ERP yang ada

\section{DAFTAR PUSTAKA}

A. P. Arsanjani, Service-Oriented Modeling and Architecture, IBM Global Services, 2004.

Chih-Yung Chen, A Design of Multiheterogeneous System Using SOA and RFID Middleware Platform, Taiwan: Department of Information Management, St. John's University., 2010.

Cox, Web Services Conceptual Architecture, IBM Software Group, 2001

G. Pohle, Component business models Making specialization real, NY USA: BM Global Services, 2005.

G. Raymond, Modeling Enterprise

\section{KESIMPULAN}

Dari pengembangan yang telah dilakukan dalam studi kasus perusahaan menggunakan pendekatan SOMA aplikasi WMS yang didukung oleh RFID dibangun dengan teknik SOA sehingga tingkat akurasi data dapat lebih akurat karena WMS mendukung pemantauan fisik penempatan barang dan penggunaan metode fifo membuat pencatatan lebih rinci dan akurat serta meminimalkan kesalahan dalam pengambilan keputusan dan penempatan barang pada Gudang. Hasil desain arsitektur yang dibangun dalam studi kasus perusahaan juga mengintegrasikan aplikasi WMS $E R P$ dengan $W e b$ dan juga $W e b$ dengan ponsel $W M S$ tanpa membuat perubahan yang besar terhadap sistem yang sudah ada. Penggunaan Implementasi WMS RFID dalam studi kasus Perusahaan adalah media yang sangat baik untuk membantu mempercepat proses tingkat diskonto WMS.

Dengan pelayanan Web yang dibutuhkan user. Kami menggunakan kelebihan modul Layanan Web untuk meminta perubahan pada perubahan pengguna untuk direalisasikan langsung pada platform. Beberapa desain label dan alat baca di perusahaan tidak akan menjadi masalah dalam pengembangan system karena sesuai dengan strategi perusahaan untuk menciptakan sistem yang terintegrasi, dan mendapatkan manfaat pengembangan dari RFID. Keuntungan terbesar dari arsitektur berorientasi layanan adalah untuk memberikan dukungan yang kuat untuk integrasi pada aplikasi-aplikasi perusahaan. Target pendekatan yang diusulkan terutama pada arsitektur berorientasi layanan (SOA) dan fitur layanan dan events yang dapat memberikan skalabilitas dan kinerja yang diinginkan.

Architecture with TOGAF A Practical Guide Using UML and BPMN, Wyman Street USA: Elsevier Inc, 2014

John, Systems Analysis And Design in A Changing World, Boston USA: Course Technology, 2009.

L. R. Ruby, RESTful Web Services, O'Reilly Media, Inc., 2007

M. E. Porter, Competitive Advantage: Creating and Sustaining Superior Performance, Simon and Schuster, 2008

P. Bhadra, An Optimized Service Oriented Middleware Design for RFID Enabled Solution, India: IRMA International Conference., 2007.

P. Kenneth, Management Information System 
ed 10, Pearson Education, 2007

Smith, Applied SOA: Service-Oriented Architecture and Design Strategies, John Wiley \& Sons, Inc., 2008.

Shang-Liang Chen, Development of Logistic Management Information System Based on Web Service Architecture and RFID
Technology, Tainan City Taiwan: Natural Sciences Publishing Cor., 2013. 